\title{
APP-LEARNING NA FORMAÇÃO CONTINUADA DE PROFESSORES
}

\section{APP-LEARNING IN THE CONTINUOUS FORMATION OF TEACHERS}

\section{APP-LEARNING EN LA FORMACIÓN CONTINUA DE PROFESORES}

\section{Eliane Silva Souza ${ }^{1}$}

\begin{abstract}
RESUMO
Este texto é uma resenha da dissertação de mestrado intitulada "App-learning na EJA em socioeducação: possibilidades e ressonâncias do App Banco de Aulas Zuppa do Saber na formação continuada das professoras", defendida no Programa de Mestrado Profissional em Educação de Jovens e Adultos da Universidade do Estado da Bahia. Trata-se de um estudo de abordagem qualitativa, baseado no referencial epistemológico da multirreferencialidade e efetivado com a Etnopesquisa Crítica/Formação que buscou compreender como o uso do App Banco de Aulas Zuppa do Saber ressoa na formação continuada de professores da Educação de Jovens e Adultos no contexto da socioeducação com privação de liberdade. As informações produzidas com as participantes, através de oficinas formativas, diário reflexivo online e questionário online, propiciaram, através da análise interpretativa, a compreensão do aplicativo estudado como um dispositivo carregado de potencialidades que reflete na formação continuada de professores oportunizando a mobilização de interatividade, a mobilização de autoria e a construção de uma dinâmica hipertextual no processo formacional.
\end{abstract}

PALAVRAS-CHAVE: App-learning. Formação continuada. Educação de Jovens e Adultos. App Banco de Aulas Zuppa do Saber. Socioeducação.

\section{ABSTRACT}

This text is a review of the master's dissertation titled "App-learning in the Youth and Adult Education in socioeducation: possibilities and resonances of App Banco de Aulas Zuppa do Saber in the continuous formation of teachers" defended in the Professional Master's Program in Youth and Adult Education of the State University of Bahia. This is a qualitative study based on the epistemological references of multi-referenciality and carried out using critical/formation ethno-research that aims to comprehend how the use of App Banco de Aulas Zuppa do Saber resonates in the continuous formation of teachers in the Youth and Adult Education in the context of socio-education with deprivation of liberty. Using an interpretative analysis, the information produced with the participants through formation workshops, a reflective online diary and online questionnaires provided an

Submetido em: 14/04/2021 - Aceito em: 20/08/2021 - Publicado em: 13/10/2021

1 Doutoranda do Programa de Pós Graduação em Educação e Contemporaneidade (PPGEduC) da Universidade do Estado da Bahia (UNEB), Mestra em Educação de Jovens e Adultos (MPEJA/UNEB), Pesquisadora do GP Interface: investigação interdisciplinar sobre a formação do educador. Membro do GP CIEJA: Cibercultura, Infância e Educação de Jovens e Adultos. Membro do Grupo de Pesquisa Formação, Tecnologias, Educação a Distância e Currículo (ForTEC). Professora da Educação Básica na Secretaria Municipal da Educação de Salvador, Bahia. 
understanding of the studied application as a device full of potential that reflects in the continuous formation process of the teachers of Youth and Adult Education providing mobilization of interactivity and authorship as well as construction of a hypertextual dynamic in the formation process.

KEYWORDS: App-learning. Continuous formation. Youth and Adult Education. App Banco de Aulas Zuppa do Saber. Socio-education.

\section{RESUMEN}

Este texto es una revisión de la tesis de maestría titulada "App-learning en la Educación de Jóvenes y Adultos en la Socioeducación: posibilidades y resonancias de la aplicación Banco de Aulas Zuppa do Saber en la formación continua de los profesores", defendida en el Programa de Maestría Profesional en Educación de Jóvenes y Adultos de la Universidad del Estado de Bahía. Se trata de un estudio cualitativo, basado en el referencial epistemológico de la Multirreferencialidad y efectuado con la Etnoinvestigación/Formación Crítica, que buscó comprender cómo resuena el uso de la aplicación Banco de Aulas Zuppa do Saber en la formación continua de profesores de Educación de Jóvenes y Adultos en el contexto de la socioeducación con privación de libertad. La información producida con los participantes, a través de talleres formativos, diario reflexivo en línea y cuestionario en línea, proporcionó, a través del análisis interpretativo, la comprensión de la aplicación estudiada como un dispositivo cargado de potencialidades que se refleja en la formación continua de los profesores proporcionando la oportunidad de movilizar la interactividad, la movilización de la autoría y la construcción de una dinámica hipertextual en el proceso formativo.

PALABRAS CLAVE: App-learning. Formación continua. Educación de jóvenes y adultos. App Banco de Aulas Zuppa do Saber. Socioeducación.

\section{INTRODUZINDO A PESQUISA}

A dissertação de mestrado intitulada "App-learning na EJA em socioeducação: possibilidades e ressonâncias do App Banco de Aulas Zuppa do Saber na formação continuada das professoras", defendida no Programa de Mestrado Profissional em Educação de Jovens e Adultos (EJA) da Universidade do Estado da Bahia (UNEB), teve como lócus de pesquisa uma escola da Educação de Jovens e Adultos vinculada à socioeducação com privação de liberdade da Rede Pública Municipal da Educação de Salvador, Bahia. O campo de estudo foi a formação de professores envolvendo App-learning, onde buscamos construir o diálogo com a cena sociotécnica e o campo epistemológico da cibercultura.

Com o exponencial avanço nas ciências e tecnologias, especialmente as tecnologias da comunicação e informação, constituiu-se um modo de viver e praticar na cultura contemporânea onde os dispositivos digitais móveis estão cada vez mais presentes em nossas vidas na condição de extensões corporais. Através dos smartphones, que portamos continuamente, nos mantemos conectados em mobilidade, recebendo e produzindo informações, ressignificando as informações para produzir conhecimentos, nos autorizando através de uma multiplicidade de linguagens e da convergência de mídias. Enfim, temos na palma das nossas mãos dispositivos potentes com os quais inovamos, protagonizando através 


\section{Revista Docência e Cibercultura}

das nossas práticas culturais em redes de autoria por todos os lugares (SANTOS, 2019; SANTOS, RANGEL, 2020).

A compreensão acerca das possibilidades de criar novas ambiências para os processos de aprendizagem e formação que essas práticas culturais contemporâneas geram nos mobilizou a desenvolver a pesquisa tendo por base o seguinte questionamento: como o uso do App Banco de Aulas Zuppa do Saber ressoa na formação continuada de professores da Educação de Jovens e Adultos no contexto da socioeducação com privação de liberdade? Para responder à questão, atuamos com o objetivo principal de compreender as possibilidades e ressonâncias do uso do referido aplicativo na formação continuada de professores do contexto onde a pesquisa foi desenvolvida.

Para concretizar a pesquisa, entendemos ser basilar a abordagem qualitativa, tendo em vista a coerência desta abordagem para os estudos que se ocupam de compreender fenômenos imersos no contexto social onde são produzidos e as significações produzidas pelos sujeitos (MINAYO, 2002; CHIZZOTTI, 2003). A multirreferencialidade foi adotada enquanto referencial epistemológico (ARDOINO, 2012; FERREIRA, 2019), pois propicia a leitura plural dos fenômenos a partir de referências distintas, sem que umas se sobreponham às outras. A Etnopesquisa Crítica/Formação (FERREIRA, 2015; MACEDO, 2004) foi o dispositivo de pesquisa que propiciou condição à nossa atuação na perspectiva de pesquisadora membro do grupo articulando os processos de pesquisa e criando ocasião para a coautoria de processos formacionais.

Com o desenvolvimento da pesquisa foi mobilizado um conjunto amplo de experiências envolvendo as Oficinas Formativas, produção de Feedback por meio de questionários online, para avaliar as experiências e efetivar os refazimentos pertinentes, e os registros das experiências e reflexões nos Diários Reflexivos online. Tais elementos se constituíram os dispositivos para produção das informações da pesquisa e foram articulados ao aplicativo vinculado ao estudo. Através da análise interpretativa (SEVERINO, 2007) e do reconhecimento das noções subsunçoras (MACEDO, 2004) efetivamos o processo de compreensão dos sentidos presentes no conjunto de informações e prosseguimos com a finalização da escrita da dissertação e com a elaboração de um conjunto de diretrizes para a construção de processos de formação continuada de professores com o aplicativo enquanto produto do mestrado profissional.

A dissertação é constituída por seis seções. A primeira cumpre o objetivo de apresentar a nossa implicação com a pesquisa, bem como fazer a exposição da questão de pesquisa e dos objetivos, sinalizar a escolha metodológica e apresentar a estrutura do texto dissertativo. $\mathrm{Na}$ 
segunda seção discutimos sobre Educação de Jovens e Adultos, socioeducação e formação continuada de professores. A terceira seção cumpre o objetivo de discutir sobre App-learning na perspectiva de inovação dos processos formacionais na cibercultura. Finalizamos esta seção apresentando a história do aplicativo estudado, sua arquitetura e as possibilidades compreendidas a partir dos processos de formação inicial e continuada aos quais se vincula.

Na quarta seção realizamos a descrição do processo metodológico experienciado, do lócus da pesquisa, dos sujeitos estudantes da escola, das professoras participantes, dos dispositivos e das noções subsunçoras reconhecidas. A seção é finalizada com os detalhes da análise interpretativa desenvolvida. Os sentidos construídos no processo da pesquisa são apresentados de forma minuciosa na quinta seção através de uma narrativa processual e da interlocução das compreensões com as parceiras e parceiros intelectuais. Finalizamos a quinta seção apresentando o produto do mestrado profissional, enquanto síntese desse processo, e prosseguimos para a última seção apresentando as considerações que conseguimos tecer na experiência de pesquisa e formação experienciada com App-learning.

\section{APP-LEARNING NA FORMAÇÃO CONTINUADA DE PROFESSORES DA EJA}

No município de Salvador, Bahia, temos as escolas situadas no contexto da socioeducação com privação de liberdade mantendo a oferta da EJA aos seus estudantes. Entendemos ser pertinente compreender a EJA como modalidade da educação básica que atende ao direito à educação aos sujeitos ao longo da vida. No caso dos sujeitos estudantes do contexto deste estudo, pode ser materializada como oportunidade de construção de aprendizagens escolares articulada ao processo de descobertas e compreensões acerca dos elementos sócio, políticos, econômicos que condicionam a produção de sujeitos adolescentes e jovens privados de liberdade.

A socioeducação é uma política pública que se efetiva através das medidas socioeducativas a partir da preponderância do caráter educativo. Porém, observa-se na análise de documentos que tratam da sua implementação e organização um processo de adjetivação em lugar de uma substantivação que fundamente os processos educativos. Na interseção entre escola e instituição encarregada de executar a medida, emergem demandas que apontam para a necessidade de compreensão sobre a educação que se pratica na socioeducação e para o desenvolvimento de formação continuada pertinente para subsidiar as práticas pedagógicas na privação de liberdade.

O contexto de atuação e os desafios desses profissionais compõem um campo que carece de 
estudos e produção de conhecimento alicerçando a sua inclusão nos currículos de formação inicial e continuada de professores. Enquanto isso não se efetiva nesse nível, as aprendizagens docentes ocorrem basicamente com a prática, já que são poucas as oportunidades de formação continuada, e estas, quando ocorrem, resultam da articulação no próprio grupo ou da articulação do grupo com parcerias dispostas à escuta sensível antes de qualquer proposição.

Nessas articulações surge a parceria da escola, contexto da pesquisa, com a UNEB através do Programa Institucional de Bolsas de Iniciação à Docência (PIBID). Esse processo resulta em diálogos e construções colaborativas de bolsistas de Iniciação à Docência com as professoras da escola. Juntos desenvolvem um processo formativo que tem, ao final, aulas produzidas, testadas, avaliadas e compartilhadas no Banco de Aulas Zuppa do Saber.

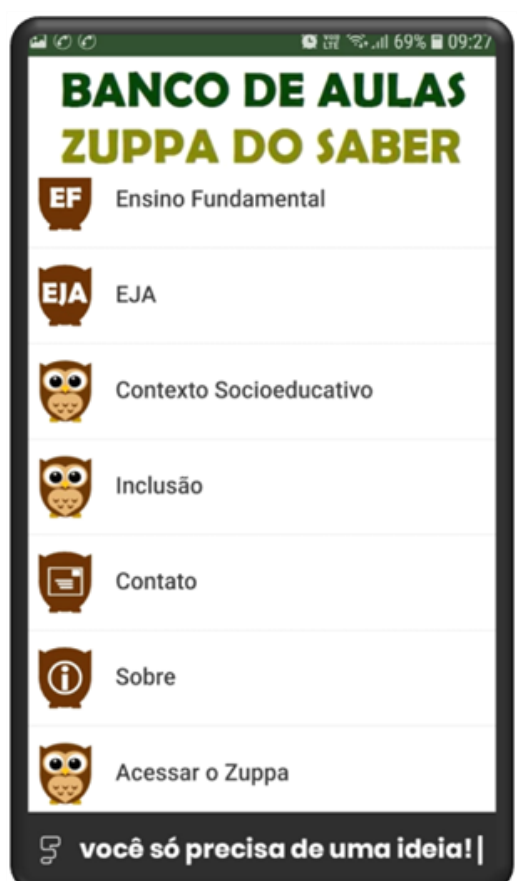

Figura 1. App Banco de Aulas Zuppa do Saber Fonte: Autora (2021).

A partir de um upgrade o banco de aulas evolui para um aplicativo (FIGURA 1). Passamos, então, a fazer questionamentos envolvendo o aplicativo que resultou na consolidação desta pesquisa sobre a formação continuada na perspectiva de App-learning. Com a pesquisa, construímos um cenário (FIGURA 2) que propiciou o desenvolvimento de um amplo e significativo conjunto de experiências articulado ao aplicativo envolvendo diversos dispositivos - Oficinas Formativas, Diário Reflexivo online e Feedback a partir de questionários online - que ampliaram a capacidade de pensar a investigação e que tiveram caráter estruturante e propositivo no que diz respeito aos resultados e conclusões da pesquisa. 
Com as Oficinas Formativas construímos um espaço plurivocal para a discussão da temática da pesquisa, análise, discussão e ressignificação de aulas disponíveis no aplicativo referente à EJA e discussão dos resultados da aplicação das aulas ressignificadas junto aos estudantes da escola. No aplicativo construímos o Diário Reflexivo online para registro das experiências desenvolvidas no processo da pesquisa e o Feedback para avaliação processual das experiências visando identificar os refazimentos necessários.

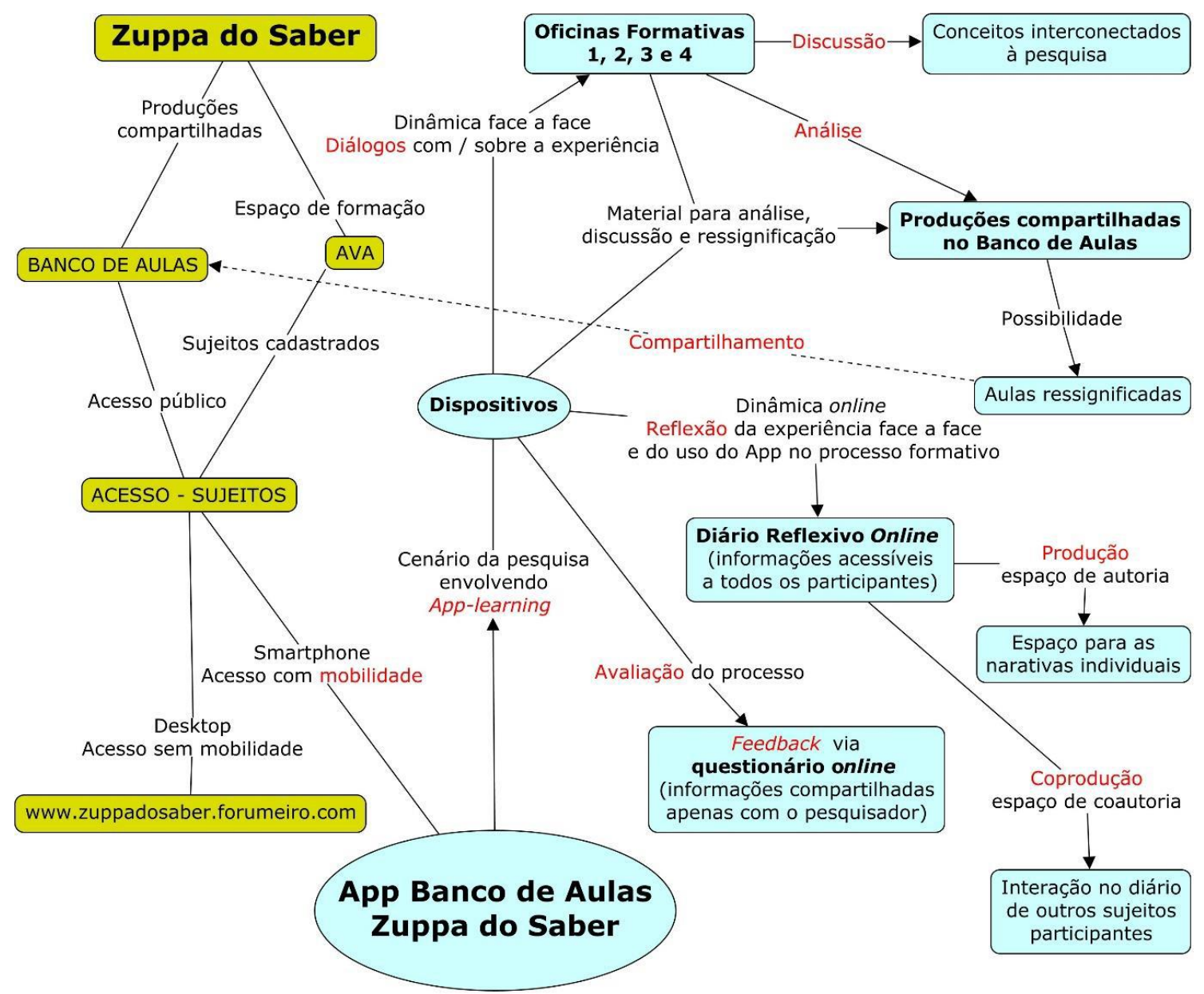

Figura 2. Mapa do processo de pesquisa

Fonte: Elaborado pela autora (2019).

O conjunto de experiências construídas se fundamentou na compreensão de App-learning enquanto

uma nova forma de aprender baseada na atribuição de novos sentidos para os aplicativos para dispositivos digitais móveis que passaram a integrar os processos de pesquisa e formação, amplificando a capacidade dos sujeitos de serem produtores, 
colaboradores, autores de uma multiplicidade de práticas. Como estas práticas envolvem dispositivos que não estão presos fisicamente, mas suscetível ao acesso a qualquer hora ou lugar, envolvendo produções plurivocais constituídas por diversas linguagens, essa característica ressoa no processo de aprendizagem, que também passa a acontecer livre das limitações impostas por um certo intervalo de tempo ou por um dado espaço físico, enriquecendo-a com a diversidade de linguagens e possibilidades, autorias e colaboração. (SOUZA, 2020)

Trata-se de possibilidades da cibercultura onde a lógica comunicacional interativa (SILVA, 2010) propicia a liberação dos polos comunicacionais. Assim, podemos atuar interventivamente nos autorizando através de uma multiplicidade de práticas em redes de autoria (SANTOS, 2019; SANTOS, RANGEL, 2020). Com as informações produzidas na pesquisa, realizamos a análise interpretativa onde reconhecemos as noções subsunçoras e prosseguimos com a interlocução com as parcerias intelectuais. Nesse processo reconhecemos emergências importantes relacionadas à interatividade, autoria e hipertextualidade.

\section{Mobilização de interatividade}

Com a conclusão dos ciclos de pesquisa, análise e ressignificação das aulas, seguidos da discussão das experiências construídas com a aplicação das aulas junto aos estudantes (FIGURA 3), em um processo marcado pela colaboração e implicação de todas as professoras, foi possível compreender a emergência que denominamos mobilização de interatividade. Por meio da interatividade o processo formacional ganhou materialidade com a atuação interventiva de todas as participantes. Assim, pudemos atuar na articulação e mobilização do processo da pesquisa favorecendo a qualidade das experiências construídas. 


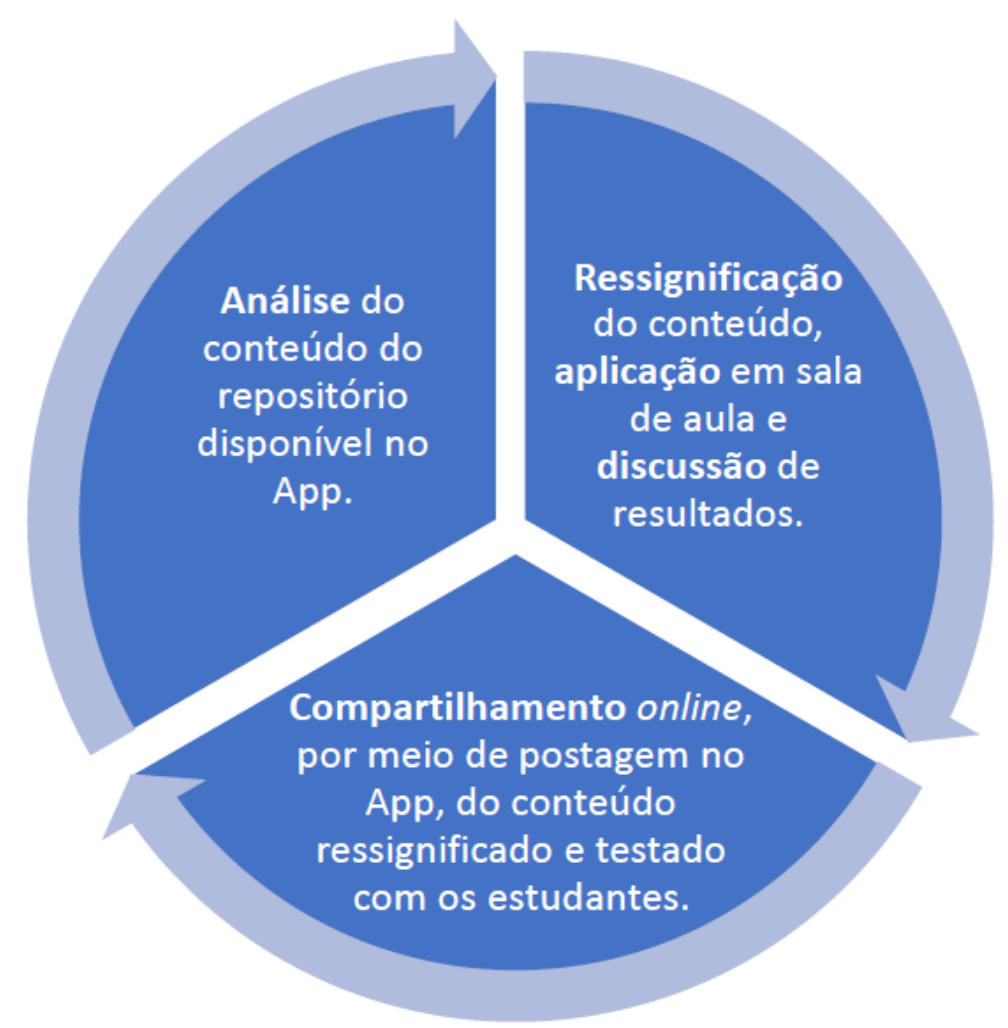

Figura 3. Ciclo de experiências construído com as Oficinas Formativas Fonte: Autora (2020).

A partir da interatividade houve ampliação da dimensão plurivocal nas oficinas; reverberação dessa lógica comunicacional nas experiências construídas junto aos estudantes; percepção do valor formacional da análise das experiências e práticas construídas pelas participantes a partir do exercício efetivo dessa atividade; construção de experiências significativas envolvendo a ressignificação das aulas do aplicativo levando em consideração ao máximo os elementos que se inter-relacionam às práticas no contexto educacional; e favorecimento da atuação propositiva do grupo em relação ao aplicativo.

\section{Mobilização de autoria}

No contexto dialógico da pesquisa as professoras foram se autorizando e a mobilização de autoria emerge de forma significativa a partir de dois elementos: o primeiro compreende o conjunto de proposições apresentadas pelo grupo envolvendo o aplicativo; o segundo envolve o reconhecimento do movimento de autoria formacional construído por cada uma com participação na pesquisa com o aplicativo, que mobilizou o processo coletivo de reflexão sobre as experiências construídas. 
Com a mobilização de autoria, observa-se a compreensão de que a formação é algo para além das formalidades acadêmicas e da emissão de certificação atestando o cumprimento de etapas de um processo formacional. A formação se efetiva nesse movimento construído com o grupo, onde os sujeitos estão sempre em relação com outros sujeitos, e vão se modificando em virtude da presença deste outro, bem como nas relações de aprendizagens consigo mesmo.

\section{A dinâmica hipertextual no processo formacional}

O conjunto de processos construídos com a experiência de pesquisa e formação oportunizou a constituição de uma dinâmica hipertextual no processo formacional, revelando o potencial dos processos formacionais na cibercultura desenvolvidos com os artefatos e dispositivos digitais em rede. Muito além de serem artefatos tecnológicos digitais usados ordinariamente, dispositivos como smartphones e a diversidade de aplicativos que comportam são estruturantes à organização de novas formas de pensar, refletindo na forma como os sujeitos constroem suas experiências e elaboram a sua aprendizagem em processos envolvendo multivocalidade, intertextualidade e interatividade, que são aspectos ligados à hipertextualidade

Ao permear a experiência formacional a lógica hipertextual propiciou: condição para que o processo fosse construído a muitas mãos, aberto à multiplicidade de conexões e sentidos possíveis, envolvendo o diálogo entre a diversidade de vozes para negociar sentidos e construir coletivamente o pensamento; construção de caminhos formacionais em rede onde as participantes atuaram interativamente; desvinculação da lógica transmissiva de conhecimentos, passando a envolver a produção coletiva a partir de ressignificação das práticas e experiências; construção maleável possibilitando avanços, retomadas e permitindo combinações variadas para a construção da experiência formacional em coautoria.

\section{CONSIDERAÇÕES}

O percurso de pesquisa e formação construído com o estudo buscou compreender como o uso do App Banco de Aulas Zuppa do Saber ressoa na formação continuada de professores da Educação de Jovens e Adultos no contexto da socioeducação com privação de liberdade. Compreendemos que a experiência formacional na cibercultura elaborada através da pesquisa gera múltiplas possibilidades de apropriação e ressignificação de artefatos e dispositivos digitais, convertendo-os em elementos potentes ao processo formacional.

Experimentar App-learning a partir do App Banco de Aulas Zuppa do Saber, foi uma 
oportunidade para construir experiências, refletir coletivamente sobre elas e tecer os fios do processo formacional. Compreendemos que estas elaborações foram potencializadas pela Etnopesquisa Crítica/Formação à medida que se trata de um dispositivo de pesquisa que oportuniza a experiência de formação para a pesquisadora e para as participantes, resultando em descobertas compartilhadas que mobilizam novas perguntas e, por conseguinte, a elaboração de novas itinerâncias.

Por fim, afirmamos que, com o caminho construído, a experiência formativa foi consolidada à medida que cada participante pode transformar-se e construir os seus processos de autorização em coautoria com seus pares, em um complexo processo de interação e alteração. O App Banco de Aula Zuppa do Saber revela-se como um dispositivo carregado de potencialidades que podem refletir no processo de formação continuada de professores da Educação de Jovens e Adultos oportunizando a mobilização de interatividade e construção de autoria, bem como oportunizando a construção de uma dinâmica hipertextual no processo formacional.

\section{REFERÊNCIAS}

ARDOINO, Jacques. Pensar a multirreferencialidade. In: MACEDO, Roberto Sidnei; BARBOSA, Joaquim Gonçalves; BORBA, Sérgio (orgs.). Jacques Ardoino \& a educação. Belo Horizonte: Autêntica Editora, 2012. (Coleção Pensadores \& Educação).

CHIZZOTTI, Antonio. A pesquisa qualitativa em ciências humanas e sociais: evolução e desafios. Revista portuguesa de educação. vol. 16 n. 002. Universidade do Minho: Braga, Portugal. 2003, p. 221-236. Disponível em:

<https://www.redalyc.org/articulo.oa?id=37416210 > Acesso em: 11 abr. 2021.

FERREIRA, Maria da Conceição Alves. A pesquisa e o itinerário investigativo em espaços multirreferenciais. Revista Observatório, Palmas, v. 5, n. 1, p. 74-93, jan-mar, 2019. Disponível em: < https://doi.org/10.20873/uft.2447-4266.2019v5n1p74> Acesso em: 11 abr. 2021.

FERREIRA, Maria da Conceição Alves. O itinerário investigativo: a Etnopesquisa Crítica/ Formação. Práxis educacional, Vitória da Conquista, v. 11, n. 20, p. 311-332, set/dez, 2015. Disponível em: < https://periodicos2.uesb.br/index.php/praxis/article/view/852> Acesso em: 11 abr. 2021.

MACEDO, Roberto Sidnei. A etnopesquisa crítica e multirreferencial nas ciências humanas e na educação. 2. ed. Salvador: EDUFBA, 2004. 


\section{Revista Docência e Cibercultura}

MINAYO, Maria Cecília de Souza. (Org.). Pesquisa social: teoria, método e criatividade. Petrópolis: Vozes, 2002.

SANTOS, Edméa; RANGEL, Leonardo. O caminhar na educação [recurso eletrônico]: narrativas de aprendizagens, pesquisa e formação. Ponta Grossa, PR: Atena, 2020. Disponível em: < https://www.atenaeditora.com.br/post-artigo/37997> Acesso em: 11 abr. 2021.

SANTOS, Edméa. Pesquisa-formação na cibercultura. Teresina: EDUFPI, 2019.

Disponível em: < http://www.edmeasantos.pro.br/assets/livros/Livro\%20PESQUISAFORMA\%C3\%87\%C3\%830\%20NA\%20CIBERCULTURA_E-BOOK.pdf> Acesso em: 11 abr. 2021.

SEVERINO, Antônio Joaquim. Metodologia do trabalho científico. 23ª ed. São Paulo: Cortez, 2007.

SILVA, Marco. Educar na cibercultura: desafios à formação de professores para docência em cursos online. Revista Digital de tecnologias cognitivas, São Paulo, n. 3, jan/jun, 2010. Disponível em: < https://revistas.pucsp.br/teccogs/article/view/52991> Acesso em: 11 abr. 2021.

SOUZA. Eliane Silva. App-learning na EJA em socioeducação: possibilidades e ressonâncias do APP Banco de Aulas Zuppa do Saber na formação continuada das professoras. 2020. 231f. Dissertação (Mestrado) - Departamento de Educação, Universidade do Estado da Bahia: Salvador, 2020. Disponível em: < https://portal.uneb.br/mpeja/wpcontent/uploads/sites/118/2021/02/VERS\%C3\%83O-FINAL-Eliane_Silva_Souzacompactado.pdf $>$ Acesso em: 11 abr. 2021. dos autores e da fonte original e sob a mesma licença. 